\title{
New Concepts for Fire Protection of Passenger Rail Transportation Vehicles
}

\author{
R. D. PEACOCK, R. W. BUKOWSKI, W. W. JONES and P. A. RENEKE \\ NIST Building and Fire Research Laboratory \\ Gaithersburg, Maryland 20899 USA
}

\begin{abstract}
Recent advances in guided ground transportation, fire test methods, and hazard analysis necessitate re-examination of requirements for fire safety. Several studies have indicated nearly random ability of current tests to predict actual fire behavior. A comparison of the approaches used in the United States, Germany, and France is presented. With the strengths and weaknesses of current methods for measuring the fire performance of materials used in rail transit systems reviewed, a direction is suggested in which most fire science-oriented organizations in the world are clearly headed - fire hazard and fire risk assessment methods supported by measurement methods based on heat release rate.
\end{abstract}

KEYWORDS: fire research; heat release rate; large scale tests; passenger vehicles; railroads; smoke; small scale tests; standards; systems approach; test methods

\section{INTRODUCTION}

In 1989, the Federal Railroad Administration (FRA) issued updated guidelines for the flammability and smoke emission for materials used in passenger rail vehicles [1]. These evolved from earlier versions [2], [3] and from guidelines developed by the Transportation Systems Center for other rail applications [4], [5], [6]. While the primary focus of these guidelines is material performance, the importance of vehicle design in providing separation between passengers and fire sources is recognized in structural fire testing requirements and in using passenger evacuation to determine acceptance criteria for such testing.

In 1990, Amtrak issued "Specification for Flammability, Smoke Emissions and Toxicity," Specification No. 352, for passenger car materials [7]. This specification describes test requirements and criteria for flammability and smoke emission nearly identical to the FRA guidelines (with the addition of toxicity testing). In addition, the Amtrak specification requires that several other factors, e.g., quantity of material present, configuration and proximity to other combustibles, be considered in combination with the material test data to develop a fire-hazard assessment which will be used to select materials on the basis of function, safety, and cost. Moreover the Amtrak specification requires testing of an assembly to provide information about the actual behavior of materials in a "real world" vehicle fire. 
The majority of the flame spread and smoke emission tests and performance criteria for vehicle interior materials contained in the National Fire Protection Association "Standard for Fixed Guideway Transit Systems" (NFPA 130) [8], intended for application to rail transit vehicles, are identical to the FRA fire safety guidelines. However, NFPA also includes requirements for other areas of fire protection. Fire risk assessment is used to evaluate smoke emission, ease of ignition, and rate of heat and smoke release, in addition to fire propagation resistance. NFPA 130 indicates that a hazard load analysis and the use of materials with appropriate properties are two means which can be used to perform the fire risk assessment. NFPA 130 encourages the use of tests which evaluate materials in certain subassemblies and the use of full-scale tests. In addition, the NFPA standard provides requirements for stations, trainways, vehicle storage and maintenance areas, emergency procedures, and communications.

Advances in rail technology, fire testing, and fire hazard analysis in the last decade necessitate re-examination of U.S. requirements for fire safety in light of these new technologies. Further review to evaluate the comparability and potential equivalence of U.S. and foreign fire safety requirements can also assist decision-makers in formulating appropriate fire safety standards in light of these new technologies. This paper provides an overview of the similarities and differences in the U.S. and foreign approaches and provides direction for the future of fire safety requirements for passenger guided ground transportation vehicles. Although this paper is primarily concerned with material requirements, it is important to note that other strategies including fire detection and suppression, vehicle design, and design and training for evacuation can play an equally important role in overall fire safety design. A more complete analysis is available [9].

\section{CURRENT REQUIREMENTS}

Fire safety in any application, including transportation, requires a multi-faceted approach. The underlying goals embodied in the guidelines and standards in various countries applicable to passenger guided ground transportation provide for the public safety from fires. These goals are universal in fire protection; only the means chosen to achieve them vary. They can be rather simply stated in the following short list [10]:

- Prevent the fire or retard its growth and spread.

- Control fire properties of combustible items.

- Provide adequate compartmentation.

- Provide for suppression of the fire.

- Protect occupants from the fire effects.

- Provide timely notification of the emergency.

- Protect escape routes.

- Provide areas of refuge where necessary.

- Minimize the impact of fire.

- Provide separation by tenant, occupancy, or maximum area.

- Maintain the structural integrity of property.

- Provide for continued operation of shared properties.

- Support fire service operations.

- Provide for identification of fire location.

- Provide reliable communication with areas of refuge.

- Provide for fire department access, control, communication, and water supply. 
To prevent the fire or retard its growth and spread, material and product performance testing is used to control the fire properties of items which represent the major fuels in the system. Vehicle design and compartmentation requirements along with limits on rate of growth perform the function of limiting fire spread. Extinguishing systems, manual or automatic, can also be used to control the fire. To protect occupants from the fire effects, detection and alarm systems notify the passengers to take appropriate actions. These systems also notify designated employees or the public fire service to begin fire fighting operations and to assist occupants. Training of personnel to react appropriately to fire incidents and system design to facilitate passenger evacuation can play an equally important part in timely passenger evacuation and fire suppression. Structural fire endurance testing of floors and partitions provide compartmentation of the fire and are intended to minimize the impact of the fire. Overall system design, personnel training, extinguishing equipment, and communication systems support fire service operations.

The FRA guidelines for conventional rail vehicles have been available since 1984 [3]. The Amtrak and NFPA [8] requirements are nearly identical, with small differences in individual material acceptance criteria, but identical test methods. The requirements are based in large part on two bench-scale test methods - ASTM E-162, "Surface Flammability of Materials Using a Radiant Energy Source" (with a variant, ASTM E-3675 for cellular materials) and ASTM E-662, "Specific Optical Density of Smoke Generated by Solid Materials". Several additional standards are specified for individual material applications. With one exception, the test methods are bench-scale tests designed to study aspects of a materials fire behavior in a fixed configuration. These test methods evaluate fire properties of individual materials to form prescriptive set of design specifications for material selection.

The French approach to material flammability bears some similarity to its U.S. counterpart, in that materials used in each application area are treated individually. The French standards provide for two types of classification of properties, "reaction to fire," (analogous to the U.S. flammability guidelines) and "toxicity" (actually a combination of smoke emission and toxicity). Acceptable pass-fail criteria vary by application and depend on both the "reaction to fire," and toxicity test results.

Numerous "reaction to fire" tests, NF P 92501 - NF P 92510 and others classify the material into one of six fire resistance categories. The "reaction to fire" tests use a complicated set of rules. For example, if a material is observed to have "significant" dripping during one of the basic flame spread tests appropriate to the material and application, then it must be tested under another test. The "toxicity" tests classify the materials on the basis of a combination of smoke emission and the toxicity of the material. The test which deals with smoke emission is FF X 10702. It is the same as the NBS Smoke Box (ASTM 662). The toxicity test is NF X 70100 which is an analytic test.

The French specification using these standards [11] is a complex system based on several classification indices, each derived from several test results. The French standards then classify the materials on the perceived risk to occupants. The intent is to provide indices which are indicative of the risk to occupants from individual materials. The difficulty with such an approach is that it must be done on a global basis, and not on the basis of individual materials. 
The German requirements address fire protection with more emphasis on efforts to minimize the impact of fire than in the U.S. or France. The German standards are described in "High-Speed Maglev Trains: German Safety Requirements (RW-MSB)" [12]. The RWMSB assigns class 4 fire protection requirements to maglev trains according of DIN 5510 part 1 published by the Deutsches Institut Für Normung e.V. (DIN) - the German Standards Institute. Class four is the highest level of protection and is applied to trains that cannot be evacuated everywhere along the track [13]. The system must be designed to maintain a safe hover long enough for the vehicle to reach a safe evacuation point - with vehicle, structural integrity, and electrical system design requirements to provide such capability. Fire endurance requirements are extensive, with application to any structural component, including floors, walls, and ceilings.

Chapter 11, of the RW-MSB requires that the supporting structures, fittings, and linings of maglev vehicles be selected and arranged to prevent or delay danger to passengers, crew, and rescue personnel caused by the development, propagation, and spread of fire. A series of tests to evaluate material performance are used to prove compliance with these requirements. These measures provide a means to prevent the fire or retard its growth and spread. Four bench-scale test methods form the core of the requirements: DIN 4102 part 1, "Fire Behavior of Building Materials and Building Components; Building Materials Concepts, Requirements and Tests," FAR 25.853, Appendix F, part IV, "Test Method to Determine the Heat Release Rate from Cabin Materials Exposed to Radiant Heat," (using the OSU apparatus for measuring heat release rate), UIC Code 564-2 OR, and ASTM F-814, "Standard Test Method for Specific Optical Density of Smoke Generated by Solid Materials for Aerospace Applications."

\section{COMPARISON OF CURRENT APPROACHES}

Bench-scale test methods are rarely interchangeable [14]. Direct comparison of individual requirements from the three countries is especially difficult due to the dramatically different philosophies of the requirements. The U.S. requirements are prescriptive in nature and apply to specific materials without consideration of interrelationships between materials during a fire. By contrast, the German requirements provide a simple performance goal with several prescriptive test methods to judge adherence to the goal. In between is the French requirements with a lofty goal of assessing risk but with a confusing range of acceptance for each individual material. Nearly all the requirements are based on bench-scale test methods.

Non-combustible Materials: Requirements in the U.S., France, and Germany all include some form of a test to define a 'non-combustible' material. The tests are similar in principle and provide similar ranking for materials, although details differ between the tests. In a true fire-engineering sense the word 'non-combustibility' would be just as inappropriate as the term 'fireproof' is today. Nonetheless, the term is widely used in building codes to indicate a material which, under certain test conditions, fails to ignite or support fire growth. The provisions in various countries and jurisdictions vary; the majority, however, are based on a 'non-combustibility' test. In North America, the most common non-combustibility test is the ASTM E 136 test. Some years ago, ASTM did decide that 'non-combustibility' was a misleading name, and so changed the name of E 136 from its original "Standard Test Method for Non-combustibility of Elementary Materials" to its present name "Standard Test Method For Behavior of Materials in a Vertical Tube Furnace at $750^{\circ} \mathrm{C}$ ". The test 
principle, however, was not altered. The method is similar in concept, although not in details, to ISO 1182 and the nearly identical DIN 4102 Part 1. Both the ISO and the ASTM methods equip a small specimen with several thermocouples, then insert it into a hot furnace. A differential temperature rise of more than the allowed amount is the primary failure criterion.

Non-combustibility (and other 'degrees of combustibility' measures) is thus based on a pass/fail determination. The results of such determinations are of very small value in quantifying the behavior of a building fire. Thus, in applications where 'non-combustibility' is sought, the real objective is a stringent limit on the heat release rate ${ }^{1}$. It is expected that the ISO 1182 method will eventually be replaced with appropriate limits on heat release rate. Eventually, the concept of non-combustibility should be laid to rest. Although this is not likely to happen quickly, significant advantages can be reaped: non-homogeneous specimens can be properly tested, and quantitative data obtained which not only satisfy code purposes but, at the same time, provide needed information for the design effort of the fire engineer.

Babrauskas, Urbas, and Richardson [15] review data from several laboratories to test the applicability of heat release rate measurements to provide equivalent classification as current test methods for 'non-combustibility.' In general, they conclude that all the tests provide similar although not identical ratings of materials and that criteria could be set based on heat release rate testing to classify current materials.

Flammability: The primary measure to judge the equivalence of the U.S., French, and German approaches to material flammability is a comparison of the primary tests used in each country. In the U.S., this test is ASTM E-162/D-3675; in France, NF P 92501NF P 92503; and in Germany, a combination of DIN 4102 part I, the OSU calorimeter, and UIC Code 564-2. ASTM E-162/D-3675 and NF P 92501 are similar radiant panel tests with comparable heat flux exposures on the specimen. These tests can be expected to provide similar ranking of materials. With the wide array of acceptance criteria in the French standards, an exact comparison of the pass-fail criteria is impossible. Litant ${ }^{14}$ puts the French requirements in context. He concludes that the French standards do not provide an improvement over the U.S. guidelines. Furthermore, the French specification uses these standards in a "most complicated and contrived manner." Although the German requirements do not include a radiant panel test, a heat release rate test is included for all materials. Such a test provides a better indicator of fire performance than the bench-scale radiant panel tests. In addition, the German standards prefer a material to be considered "non-combustible", which further limits it peak heat release rate. The German requirements provide a stricter requirement which should better predict real-scale fire behavior.

For floor coverings, the U.S. and France include a radiant panel test. Although test details differ, the heat fiux exposure in the French requirement in nearly one half the exposure in the U.S. requirement $\left(3.5 \mathrm{~kW} / \mathrm{m}^{2}\right.$ versus $\left.6 \mathrm{~kW} / \mathrm{m}^{2}\right)$. The U.S. requirement should provide a stricter rating criteria. The German requirements do not include a specific test for floor covering. Rather, it is treated identically to other interior lining elements.

\footnotetext{
1 Some building codes have an avowed intent to exclude materials showing 'continued progressive combustion' due to smoldering or glowing by the use of non-combustibility requirements. However, materials showing these behaviors exhibit heat release values high enough that a sufficiently stringent heat-release-based criteria will also exclude such materials.
} 
Notably missing from the German requirements is a testing requirements for insulation. Although typically used in unexposed locations, it can contribute significantly to fire growth once exposed. Such a test should be included since such materials have been significantly involved in actual fire incidents in passenger guided ground transportation vehicles.

The remaining flammability requirements are mostly based on small-burner tests which have been shown to provide little or no capability to predict actual fire behavior. Most of these tests provide a measure of resistance to ignition by a small ignition source and little else.

Smoke Emission: Smoke emission tests in the three countries are all based on variants of the same smoke density measurement apparatus using small samples in a static environment. In the U.S. and France, the NBS Smoke Density Chamber is used. In Germany, an early variant of this device, the XP2 apparatus is specified. In addition, a variant of the apparatus, ASTM F-814, is used. In the context of use, it is identical to ASTM E-662. Acceptance criteria for the test is stricter in Germany than in the U.S. or France.

However, these tests have been shown to provide little indication of actual fire behavior. Like the tests for flammability, it has become apparent over the last ten years that smoke can be best measured in a dynamic test which best simulates actual end-use burning behavior. Requirements for a bench-scale test to measure smoke have been proposed [16]:

- Measure fire properties in such a way that they can be used for purposes other than simple rankings or pass/fail criteria.

- Measure smoke obscuration together with those fire properties of considerable fire hazard interest, principally the rate of heat release.

- Utilize tests which have proven to give results that are representative of the corresponding property in real-scale.

- Allow for calculations to compensate for complete sample consumption, characteristic of bench-scale tests.

The only tests in existence which fulfill these requirements are those based on heat release rate calorimetry. Hirschler [16] concludes that the best way to measure smoke obscuration in a meaningful way for real-scale fires is to use a bench-scale heat release rate test such as the cone calorimeter (or the OSU calorimeter) with compensation for incomplete burning of materials in a bench-scale test. He finds good correlation with real-scale fires for a range of materials.

Fire Endurance: Both the U.S. and Germany include requirements for large-scale fire endurance testing. In the U.S., ASTM E-119 is used; in Germany, the equivalent method is specified in DIN 4102, parts 2 and 5. Both are large-scale furnace tests with nearly identical time-temperature requirements for the furnace. In Germany, the requirements clearly apply to wall partitions (DIN 4102, part 2) and are likely to include floors and ceilings as part of a requirement for support structures such that "a breakdown of stability due to burn damage or heating and a transmission of fire is prevented or at least adequately delayed." The minimum test duration in the German requirements is twice that included in the U.S. guidelines. 
In testing large-scale fire endurance, the German requirements are clearly more severe, with the requirements applicable to floors, ceilings, and wall partitions, along with a test duration double the U.S. requirement. There are no French requirements for fire endurance testing.

\section{MATERIAL REQUIREMENTS BASED ON HEAT RELEASE RATE TESTING}

Most important in all three approaches is the dependence on outdated bench-scale test methods. For most of the tests, considerable evidence questions their ability to predict realscale fire test behavior. Advances in fire safety engineering have been made in the decade since the original development of the current U.S. guidelines for material selection in passenger guided ground transportation. Better understanding of the underlying phenomena governing fire initiation and growth have led to the development of a new generation of standard test methods which can better predict the real-scale burning behavior of materials and assemblies from bench-scale measurement methods based on a material's heat release rate. These advances should be incorporated in future designs of passenger guided ground transportation systems.

In the majority of fire cases, the most crucial question that can be asked by the person responsible for fire protection is: 'How big is the fire?' Put in quantitative terms, this translates to: 'What is the heat release rate (HRR) of this fire?' Recently NIST examined the pivotal nature of heat release rate measurements in detail [17]. Not only is heat release rate seen as the key indicator of real-scale fire performance of a material or construction, heat release rate is, in fact, the single most important variable in characterizing the 'flammability' of products and their consequent fire hazard. Examples of typical fire histories illustrate that even though fire deaths are primarily caused by toxic gases, the heat release rate is the best predictor of fire hazard. Conversely, the relative toxicity of the combustion gases plays a smaller role. The delays in ignition time, as measured by various Bunsen burner type tests, also have only a minor effect on the development of fire hazard.

Three types of tests are seen as necessary to judge the fire behavior of materials used in passenger guided ground transportation:

(1) The Cone Calorimeter, ASTM 1354, can provide multiple measure of fire performance for materials and assemblies used in the construction of guided ground transportation vehicles. These include ignitability; heat release rate; and release rates for smoke, toxic gases, and corrosive products. Although potential acceptance criteria for passenger guided ground transportation have been proposed, additional testing is required to identify actual criteria in consideration of the current state-ifthe-art for materials used in passenger guided ground transportation vehicles.

(2) Standard fire endurance testing, such as specified in ASTM E-119, provides a measure of the ability of a given construction to prevent the spread of fire from on compartment to another or from the underside of a vehicle to the interior.

(3) Initial reference real-scale testing will always be needed for any product category. Bench-scale tests can then, if suitably validated against these real-scale fires, be used to provide for most of the needed product testing. Thus, the large-scale test will rarely be needed in practice. But, it must be available for those situations where the bench-scale test is not applicable. 


\section{FIRE HAZARD ANALYSIS}

The primary goal of fire safety regulation (after preventing the ignition) is to limit the impact of the fire on a construction and its occupants. This has traditionally been addressed by placing a limit on the burning behavior of products in some standard test method which was intended to simulate a realistic threat. For example, classical fire tests such as the ASTM E-84 which evaluates the performance of interior finish products when exposed to a standard fire condition representative of a broad range of applications for these products. The results of these test methods can be misleading when applied to products without proper regard to their context of use, such as the testing of low density plastics in the E-84. In many cases there is only a tenuous connection between the results of that test and the property that was being checked. This applies to toxicity, flame spread, and ease of ignition among others.

In general it is difficult to make the 'cross walk' necessary to substantiate the assertion that some critical property was measured. However, the advent of modeling, developed mostly over the past decade, is having a profound impact on our ability to evaluate realistically the fire hazards of materials and products in their actual context of use. A subsidiary benefit of these techniques is that it should be possible to predict the properties of products in the test configuration to understand exactly what was being measured, should there be an interest in pursuing the test apparatuses.

We no longer need to depend on the stand-alone methods for determining the degree of fire safety afforded by a product. We can now integrate the complex interactions of products with each other in the context of their application and use, interactions which are not considered in traditional test methods. We can determine how the deficiencies of one product are offset by the strengths of another, resulting in a safe combination. A good example of this is the use of blocking layers in aircraft seats [18] which protect the foam core for sufficient time to allow safe evacuation of the passengers. This allows retention of the foam's benefits of comfort and light weight and still provide an appropriate level of safety.

It is the newly-emerging science of predictive fire modeling that enables us to evaluate the combination of a product and the environment in which it is being used. A primary example of the application of this field is in assessing smoke toxicity from the burning of concealed combustibles [19]. Here, the surroundings of the product affect its burning behavior as well as the movement of the smoke to where people might be harmed. Of even more importance, the models allow one to keep track of the contribution of the product, relative to the smoke produced by other combustible items which may be involved. This is a breakthrough, since only the total smoke toxicity can be measured in tests.

Ultimately, fire hazard analysis utilizing necessary data from bench-scale heat release rate measurements can provide a true assessment of the contribution of a material or assembly to the overall fire hazard for identified fire scenarios in passenger guided ground transportation.

Quantitative hazard analysis techniques have the potential of providing significant cost savings. Alternative protection strategies can be studied within the hazard analysis framework to give the benefit-cost relation for each. In addition, measures are evaluated as a 
system with their many interactions, including the impact of both structure and contents. Providing these alternatives promotes design flexibility which reduces redundancies and cost without sacrificing safety. New technology can be evaluated before it is brought into practice, thus reducing the time lag currently required for code acceptance. Thus, quantitative hazard analysis is a powerful complement to existing codes and standards and a useful tool in evaluating improvements to them.

\section{CONCLUSION}

Considerable advances in fire safety engineering have been made in the decade since the original development of the current U.S. guidelines for material selection in passenger guided ground transportation. Better understanding of the underlying phenomena governing fire initiation and growth have led to the development of a new generation of test methods which can better predict the real-scale burning behavior of materials and assemblies. At the same time, advances in fire and hazard modeling are leading a revolution in the analysis of a materials overall contribution to fire hazard in a particular application. These advances should be incorporated in future designs of passenger guided ground transportation systems.

\section{REFERENCES}

1 Federal Railroad Administration, Rail Passenger Equipment; Reissuance of Guidelines for Selecting Materials to Improve Their Fire Safety Characteristics, Federal Register, Vol. 54, No. 10, 1837-1840 (1989).

2 Federal Railroad Administration, Rail Passenger Equipment; Reissuance of Guidelines for Selecting Materials to Improve Their Fire Safety Characteristics, Federal Register, Vol. 49, No. 217, 44052-44584 (1984).

3 Federal Railroad Administration, Rail Passenger Equipment; Guidelines for Selecting Materials to Improve Their Fire Safety Characteristics, Federal Register, Vol. 49, No. 162, 33076-33078 (1984).

4 U. S. Urban Mass Transportation Administration, Recommended Fire Safety Practices for Rail Transit Materials Selection, Federal Register, Vol. 49, No. 158, (1984).

5 Hathaway, W. T. and Flores, A. L., Assessment of the Benefits and Costs Associated with the Adoption of the Recommended Fire Safety Practices for Rail Transit Materials Selection, U. S. Department of Transportation Report No. UMTA-MA-06-0098-81-3 (1980).

6 Hathaway, W. T. and Litant, I., Rationale for Recommended Fire Safety Practices for Rail Transit Materials Selection, U. S. Department of Transportation Report No. UMTA-MA-06-0098-82-1 (1983).

7 Specification for Flammability, Smoke Emissions and Toxicity, Amtrak Specification No. 352, National Railroad Passenger Corporation, April 291991.

8 National Fire Protection Association, NFPA 130, Standard for Fixed Guideway Transit Systems, 1990 edition, NFPA, Quincy, MA (1990).

9 Peacock, R. D., Bukowski, R. W., Jones, W. W., Reneke, P. A., and Babrauskas, V., Fire Performance of Passenger Guided Ground Transportation Systems - A Review of the Existing Methods and of New Concepts, Natl. Inst. Stand. Technol., to be published.

10 Bukowski, R. W. and Tanaka, T., Toward the Goal of a Performance Fire Code, Fire and Materials. Vol. 15, 175-180 (1991).

11 NF F 16-101, 102 Railway rolling stock, Fire Behaviour, Choice of Materials 
(Application to Electrical Equipment) edite par l'association francaise de normalisation (afnor), tour europe cedex 7, 92080 paris la defense, FRANCE (July, 1989).

12 High-Speed Maglev Trains: German Safety Requirements RW-MSB (translation of German Regelwerk Magnetschnellbahnen Sicherheitstechnische Anforderungen), U. S. Department of Transportation, Report No. DOT/FRA/ORD-92/01 (1992).

13 Preventive Fire Protection in Railway Vehicles; Levels of Protection, Fire Preventive Measures and Certification, DIN 5510 Part 1, Deutsches Institut Für Normung e.V. (1988). 14 Litant, I., Comparison of U.S. and French Regulations for Rail Transit Fire Safety, presented at Thirteenth International Conference on Fire Safety, San Francisco, CA (1988). 15 Babrauskas, V., Urbas, J., and Richardson, L., Non-combustibility, Chapter 8(e) in Heat Release in Fires, Babrauskas, V. and Grayson, S. J., Eds., Elsevier Applied Science, New York (1992).

16 Hirschler, M. M., How to Measure Smoke Obscuration in a Manner Relevant to Fire Hazard Assessment: Use of Heat Release Calorimetry Test Equipment, J. of Fire Sci., Vol. 9, pp 183-222 (1991).

17 Babrauskas, V., and Peacock, R.D., Heat Release Rate: The Single Most Important Variable in Fire Hazard, Fire Safety J., Vol. 18, No. 3, 255-272 (1992).

18 Hall Jr., J.R., and Stiefel, S.W., Decision Analysis Model for Passenger-Aircraft Fire Safety with Application to Fire-Blocking of Seats, NBSIR 84-2817, Nat. Bur. Stand., (U.S.) Gaithersburg, MD 20899 (1984).

19 Bukowski, R.W., Toxic Hazard Analysis of Plenum Cables, Fire Technology, Vol. 21, No. 4, pp 252-266, (1985). 